\title{
Volumetric evaluation of temporal bone structures in the cases with bilateral tinnitus: clinical and morphometrical study
}

\author{
N. Gocmen-Mas ${ }^{1}$, O. Kahveci ${ }^{1}$, S. Lafcı Fahrioğlu ${ }^{3}$, N. Okur ${ }^{4}$, S. Canan ${ }^{5}$, N. Demirci Yonguc ${ }^{1}$, \\ O. Özel ${ }^{6}$, S. Karabekir ${ }^{7}$
}

\begin{abstract}
${ }^{1}$ Department of Anatomy, Faculty of Medicine, Dokuz Eylül University, Turkey
${ }^{2}$ Department of Otolaryngology, Faculty of Medicine, Afyon Kocatepe University, Turkey

${ }^{3}$ Department of Anatomy, Faculty of Medicine, Near East University, Cyprus

${ }^{4}$ Department of Radiology, Faculty of Medicine, Afyon Kocatepe University, Turkey

${ }^{5}$ Department of Physiology, Faculty of Medicine, Üsküdar University, Turkey

${ }^{6}$ Otolaryngology Clinic, Afyon Kocatepe State Hospital, Turkey

${ }^{7}$ Department of Neurosurgery, Faculty of Medicine, Dokuz Eylül University, Turkey
\end{abstract}

[Received: 10 April 2017; Accepted: 27 April 2017]

Background: Tinnitus is the recognition of sound in the absence of any external auditory stimulus to the noise of ringing in the ears. Middle ear aeration carries important role for ossicular coupling and normal hearing. There is restricted morphometric data on the cases with bilateral tinnitus.

Materials and methods: In this study we evaluated hearing findings of 18 cases with subjective nonpulsatile bilateral tinnitus and also morphometry and volumetry of temporal bone substructures on the computed tomography images using stereological method compared with the gender and age matched 12 healthy subjects. Duration of tinnitus, exposing acoustic trauma orland high level noise levels, evaluation of middle ear volume, jugular bulb levels, distances between jugular bulb and both oval window and middle ear were evaluated.

Results: Both males and females with tinnitus showed worse hearing thresholds through bone and air conductions than healthy subjects but it was not statistically significant. Pure tone thresholds through bone and air conductions were not statistically different in both sexes with bilateral tinnitus. Right middle ear volume of the cases with bilateral tinnitus was mean $5.57 \mathrm{~cm}^{3}$ for males and $5.64 \mathrm{~cm}^{3}$ for females; and also the left middle ear volume of the cases with bilateral tinnitus was mean $5.87 \mathrm{~cm}^{3}$ for males and $5.65 \mathrm{~cm}^{3}$ for females. There were no significant differences between the cases with bilateral tinnitus and the control subjects according to the side of the body.

Conclusions: The data on the hearing findings and morphometrical evaluation of the cases with bilateral tinnitus may be important for anatomists and clinicians. (Folia Morphol 2018; 77, 1: 57-64)

Key words: bilateral tinnitus, temporal bone, computed tomography, stereology, clinical evaluation 


\section{INTRODUCTION}

Chronic tinnitus is experienced in about 5-15\% of the general population and severely impacts the quality of life in about $1-2 \%$ in the population $[3,15,30]$. Abnormal auditory input, for example by cochlear damage, is considered as a frequent trigger, but not considered as a sufficient condition to develop chronic tinnitus [23]. In addition, changes in both auditory cortex and several neocortical structures have been detected affecting the auditory pathways [7]. Functional magnetic resonance imaging (fMRI) and structural MRI, positron emission tomography (PET), single photon emission computed tomography (SPECT) as well as electroand magnetoencephalography (EEG, MEG) have been used to identify brain structures involved in tinnitus $[2,20,27]$. Tinnitus is a well-known complaint that has been admitted to otolaryngology, neurology and neurosurgery clinics [24, 29]. However, underlying pathology and aetiological factors and treatment of tinnitus is not still clear $[12,21]$. Tinnitus may result from venous pathologies on jugular bulb (JB), acoustic neurinoma, internal acoustic tumours, otologic problems such as Meniere disease, acoustic trauma, ototoxic drugs etc., and concomitant hearing loss without any otologic, neurologic disease or any constitutional lesion $[5,9,15,28,30]$. In the literature, some authors claimed the cause of tinnitus might be from different factors such as, racial, physiological, genetic and anatomical factors $[8,28,30]$. Musculature and joint problems on the head and neck region are commonly related with tinnitus and have been theorised to carry an important role in tinnitus' aetiology $[6,16]$. Neural hyperactivity in the auditory cortex may cause bilateral tinnitus. Several researchers have searched the use of low frequency $(1 \mathrm{~Hz})$ repetitive transcranial magnetic stimulation as a potential regulator of the hyperactivity [4].

Numerical evaluation on computed tomography (CT) may provide diagnostic approach and aetiological clues. Stereological volumetrical analysis may have an importance to find out the differences between tympanic cavity on the healthy subjects and the cases of bilateral tinnitus.

The stereological method is fast, efficient, unbiased, cheap and safe. It is based on point counting approach using superimposed transparent grid on $\mathrm{CT}$ images $[1,11]$.

\section{MATERIALS AND METHODS}

\section{Clinical analysis}

Thirty-six ears from a group of 18 patients (8 male, 10 female) with bilateral tinnitus who applied to otolaryngology from Afyon Kocatepe State Hospital were subjected to the retrospective study. The cases that had subjective nonpulsatile tinnitus and previously had temporal bone CT examination were accepted to the study according to the file records of the patients. The patients with otologic, neurologic or systemic diseases and the patients using ototoxic agents were excluded from the study. The patients who had objective and pulsatile tinnitus were not included in the study. Twelve control subjects ( 5 male, 7 female) with no sensation of tinnitus were accepted as healthy control group. The ears were divided into two groups as "bilateral tinnitus" and healthy "control" groups. Further, the groups were divided into two groups as "right" and "left". Temporal CT scans and audiometric results of patients were examined, retrospectively.

\section{Computed tomographic image analysis}

Eighteen right-handed patients' temporal CTs who had bilateral tinnitus were included into the study according to file records. The control group included the cases who admitted to polyclinic with headache complaint and had temporal CT images. All evaluations were performed with Siemens Samoten Emotion multi-slice CT machine (Germany) multi-slice CT machine from the Afyon State Hospital. Patients who met the inclusion criteria underwent multi-detector row CT examination. Transverse scans were acquired in the helical mode with $120 \mathrm{mAs}, 1$-s rotation time, 1-mm section thickness, $1-\mathrm{mm}$ table feed and rotation. All images were displayed at a window centre of $700 \mathrm{HU}$ and a window width of $4000 \mathrm{HU}$. The retrospective morphometric study was approved by the Local Ethics Committee of Antalya Training and Research Hospital. According to achieve file data, none of the participants was taking medication for 7 days or more at the time of scanning. The clinical evaluation ascertained both the personal and family history and physical and neurological conditions of the subjects, via checking patients' file records. Patients who had lifetime history of neurological illness, migraine with aura, head injury, a history of any chronic medication use, substance or alcohol abuse, epilepsy, schizophrenia, bipolar disorder, major medi- 


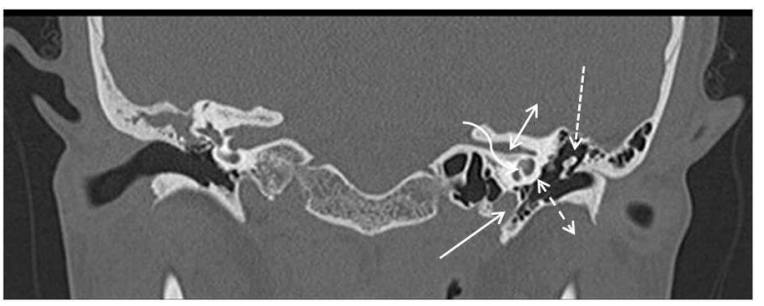

Figure 1. Coronal temporal computed tomography sections including temporal bone and ear structures. Long arrow - jugular bulb; curved arrow - carotid canal; double headed arrow - Eustachian tube; double headed dotted arrow - promontorium; dotted arrow - head of the malleus.

cal illnesses (including cardiac disease and diabetes) were excluded from the study. Additionally, none of the patients had history of acoustic trauma.

\section{Morphometrical analysis}

Middle ear volumes, distance between internal acoustic meatus and JB, distance between oval windows and JB of each image were evaluated by two anatomists. The diameters were measured three times manually using callipers for each $\mathrm{CT}$ image, bilaterally. The internal auditory canal was identified on the medial border of the petrous bone. The level of the JB was defined on the coronal, sagittal and axial sections (Fig. 1). The evaluation of JB levels such as epitympanic, mesotympanic, hypotympanic and infratemporal were documented through monitoring and recording on CT images of both the patients' and control subjects'. Jugular bulb levels are identified and labelled based on the location of its apex with respect to the sulcus tympanicus: if the apex of the JB is located superior to the sulcus tympanic sulcus it is called "epitympanic", if the apex of the $J B$ is located between upper and lower part of the tympanic sulcus it is called "mesotympanic", if the apex of the JB is located inferior to the tympanic sulcus it is called "hypotympanic", if the apex of the JB is located inferior to the level of the middle ear in the temporal bone is called "infratemporal". The documentation of the results was taken through the measurements of the middle ear volumes and the internal acoustic canal wideness's. Additionally, the distances from the JB to oval window and middle ear were also evaluated. Ear substructures were shown at epitympanic, mesotympanic and hypotympanic levels on transvers sections (Figs. 2-4). All measurements were performed blinded to subject details and data of any other results. An optimal plan was

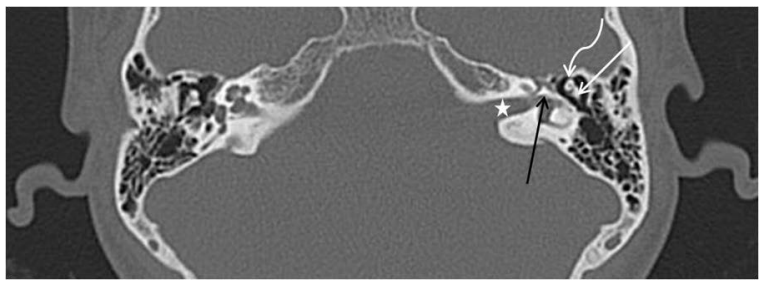

Figure 2. Axial temporal computed tomography sections through the epitympanum, the middle ear space just superior to the tympanic membrane. Curved arrow - head of the malleus; straight arrow - short process of the incus. Genu of the facial nerve (geniculate ganglion) is also indicated with black arrow. The internal auditory canal (indicated with asterisk) is the indentation on the medial border of the petrous part of temporal bone. The diameter of the internal auditory canal was measured at the internal opening of the acoustic canal.

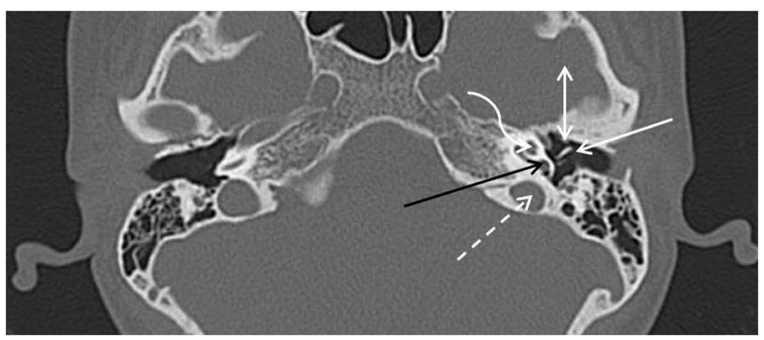

Figure 3. Axial temporal computed tomography sections through the mesotympanum. White straight arrow - tympanic membrane; double headed arrow - manubrium mallei; curved arrow — carotid canal; black arrow — promontorium; dotted arrow — jugular bulb.

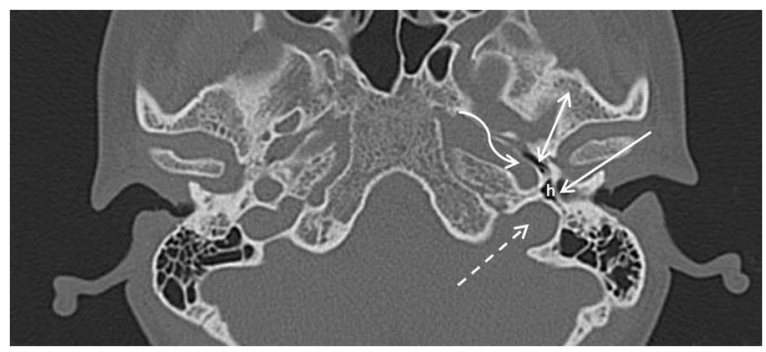

Figure 4. Axial temporal computed tomography sections through the hypotympanum (h). Straight arrow - tympanic membrane; curved arrow - carotid canal; double headed arrow - Eustachian tube; dotted arrow — jugular bulb.

taken as the smallest size of anisotropic structures that may be measured in stereological volumetric analysis of axial temporal CT sections. Original CT images were exported as .tiff image files which were further subjected to stereological analysis. A uniform point-grid with a point-associated area of $0.625 \mathrm{~cm}^{2}$ was randomly superimposed on each CT image using the "grid" plug-in installed with films. Points hitting the middle ears were manually counted for 


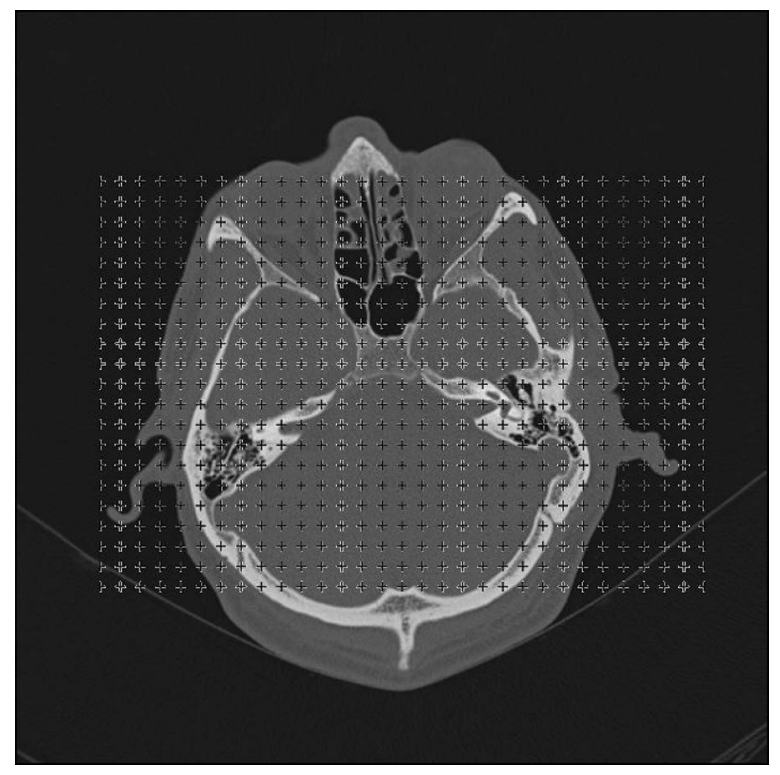

Figure 5. The stereological point counting method was shown on the transvers computed tomography section of the temporal bone.

volume estimation, bilaterally. The volumes were also estimated by using the Cavalier's principle of stereological methods as described in the previous studies $[14,19-22]$ by utilising the formula given below: $\mathbf{V}=\mathbf{t} \times[(\mathrm{SU}) \times d] / S L]^{2} \times P$, where, $t$ is the section thickness, SU is the scale unit (the real length of the scale marked on the CTs), $d$ is the distance between two points in the point grid, SL is the scale length (the actual measure of the scale on CTs) and $\mathrm{P}$ is the number of points counted. All data have been entered a previously-prepared Microsoft excel spreadsheet for automatic calculation of the outcomes of the above formula and the statistical evaluation parameters including the nugget variance and the coefficient of error (CE). The CE of the study was calculated according to Nyengaard and Marcussen [25].

In order to evaluate volumetric asymmetry between right and left middle ears, middle sagittal sections were identified by clear visualisation of the area. The point counts belonging to the middle section was divided by two and the results were added to total point counts for each area separately, and thus, a volume value for each middle ear were estimated. The stereological point counting method is demonstrated in Figure 5.

\section{Statistical analysis}

Shapiro-Wilk's test was used to assess the normality of distributions of the variables, and Levene's test was used to assess the homogeneity of variances in the different groups. Variables with normal distribution and homogeneous variance were analysed by the Student's $t$ test for comparison of the two independent groups and paired sample $t$ test for dependent groups. Hence, parametric test assumptions were not available for some variables, the comparisons of these groups were performed with the Mann-Whitney $U$ test for two independent groups and the Wilcoxon signed rank test for dependent groups. The results of tests were expressed as the number of observations ( $n$ ), the mean \pm standard deviation (mean \pm SD). The difference of JB levels between the groups were assessed with $\chi^{2}$ crosstabulation test and further Yates corrections for continuity were performed. Data analyses were performed with SPSS 15.0 software (Statistical Package for the Social Sciences, version 15.0, SSPS Inc., Chicago IL, USA). A p value less than 0.05 was considered statistically significant.

\section{RESULTS}

\section{Clinical data}

The mean age of the cases was $60.33 \pm 8.73$ years (range 43-74 years). The mean duration of cases' complaint of bilateral tinnitus was $12.60 \pm 10.94$ months. The mean pure tone thresholds through air and bone conductions in females and males were given in Tables 1 and 2, respectively. Statistical analysis did not reveal significant differences between both right and left sides in two sexes of both bilateral tinnitus and control groups ( $p s>0.05 ; p$ values are given in Tables 1 and 2). Both males and females with bilateral tinnitus showed worse hearing thresholds through bone and air conductions than healthy control subjects. However, statistical analysis did not reveal any significant difference regarding the pure tone thresholds in right and left sides of bilateral tinnitus and control cases ( $p s>0.05 ; p$ values are given in Tables 1 and 2).

\section{Morphometrical data}

The mean volumetric, morphometric measurements and distances between the JB and some important landmarks in right and left sides of both groups according to sex were shown at Table 3 . There were no significant differences regarding the middle ear volume, internal acoustic meatus diameter, JB diameter, the distance between the JB and middle ear and the distance between the JB and oval window between 
Table 1. Pure tone (PT) thresholds through bone and air conductions in both sides of females

\begin{tabular}{|c|c|c|c|c|c|c|c|c|}
\hline \multirow[t]{2}{*}{ Females } & \multicolumn{3}{|c|}{ Bilateral tinnitus $($ mean $\pm S D)(n=10)$} & \multicolumn{3}{|c|}{ Control (mean \pm SD) $(n=7)$} & \multicolumn{2}{|c|}{$\mathbf{P}^{*}$} \\
\hline & Right ear & Left ear & $\mathbf{P * *}$ & Right ear & Left ear & $\mathbf{P}^{* *}$ & $\mathbf{R}$ & $\mathbf{L}$ \\
\hline PT bone $[\mathrm{dB}]$ & $18.38 \pm 3.74$ & $19.38 \pm 3.34$ & 0.587 & $15.00 \pm 3.33$ & $12.74 \pm 7.68$ & 0.915 & 0.152 & 0.070 \\
\hline PT air [dB] & $27.36 \pm 6.33$ & $28.03 \pm 4.00$ & 0.798 & $20.68 \pm 9.03$ & $23.16 \pm 5.54$ & 0.222 & 0.183 & 0.088 \\
\hline
\end{tabular}

*P values were given for Student's $t$ test: For comparisons of right and left ears; **P values were given paired sample $t$ test: For comparisons of tinnitus and control ears in right and left sides; $\mathrm{R}$ and $\mathrm{L}$ — comparison of right $(\mathrm{R})$ and left $(\mathrm{L})$ ears in bilateral tinnitus and control cases

Table 2. Pure tone (PT) thresholds through bone and air conductions in both sides of males

\begin{tabular}{|c|c|c|c|c|c|c|c|c|}
\hline \multirow[t]{2}{*}{ Males } & \multicolumn{3}{|c|}{ Bilateral tinnitus (mean $\pm S D)(n=8)$} & \multicolumn{3}{|c|}{ Control (mean $\pm S D)(n=5)$} & \multicolumn{2}{|c|}{$\mathbf{P}^{*}$} \\
\hline & Right ear & Left ear & $\mathbf{P} * *$ & Right ear & Left ear & $\mathbf{P * *}$ & $\mathbf{R}$ & $\mathbf{L}$ \\
\hline PT bone $[\mathrm{dB}]$ & $17.62 \pm 3.24$ & $15.98 \pm 5.21$ & 0.568 & $13.86 \pm 6.69$ & $11.22 \pm 1.08$ & 0.552 & 0.315 & 0.181 \\
\hline PT air [dB] & $22.64 \pm 4.01$ & $24.52 \pm 3.61$ & 0.226 & $20.50 \pm 5.35$ & $22.21 \pm 2.81$ & 0.380 & 0.539 & 0.385 \\
\hline
\end{tabular}

${ }^{*} \mathrm{P}$ values were given for Student's $\mathrm{t}$ test: For comparisons of right and left ears; ${ }^{* *} \mathrm{P}$ values were given paired sample $\mathrm{t}$ test: For comparisons of tinnitus and control ears in right and left sides; $\mathrm{R}$ and $\mathrm{L}$ - comparison of right $(\mathrm{R})$ and left $(\mathrm{L})$ ears in bilateral tinnitus and control cases

Table 3. Mean values of morphometric measurements of the cases with bilateral tinnitus and control group according to sex

\begin{tabular}{|c|c|c|c|c|c|c|c|c|}
\hline & \multicolumn{4}{|c|}{ Bilateral tinnitus (mean $\pm \mathrm{SD}$ ) } & \multicolumn{4}{|c|}{ Control (mean \pm SD) } \\
\hline & \multicolumn{2}{|c|}{ Right ear } & \multicolumn{2}{|c|}{ Left ear } & \multicolumn{2}{|c|}{ Right ear } & \multicolumn{2}{|c|}{ Left ear } \\
\hline & $\begin{array}{c}\text { Male } \\
(\mathrm{n}=8)\end{array}$ & $\begin{array}{l}\text { Female } \\
(n=10)\end{array}$ & $\begin{array}{c}\text { Male } \\
(\mathrm{n}=8)\end{array}$ & $\begin{array}{l}\text { Female } \\
(n=10)\end{array}$ & $\begin{array}{c}\text { Male } \\
(n=5)\end{array}$ & $\begin{array}{l}\text { Female } \\
(\mathrm{n}=7)\end{array}$ & $\begin{array}{c}\text { Male } \\
(\mathrm{n}=5)\end{array}$ & $\begin{array}{l}\text { Female } \\
(\mathrm{n}=5)\end{array}$ \\
\hline ME volume $\left[\mathrm{cm}^{3}\right]$ & $5.57 \pm 0.70$ & $5.64 \pm 0.66$ & $5.87 \pm 1.08$ & $5.65 \pm 1.09$ & $5.49 \pm 0.40$ & $6.22 \pm 0.75$ & $5.25 \pm 0.81$ & $6.15 \pm 0.63$ \\
\hline IAM diameter [mm] & $8.70 \pm 1.68$ & $8.15 \pm 1.58$ & $8.54 \pm 1.33$ & $8.30 \pm 1.54$ & $9.18 \pm 0.67$ & $8.07 \pm 1.04$ & $10.56 \pm 3.18$ & $8.02 \pm 0.90$ \\
\hline JB diameter [mm] & $7.08 \pm 0.72$ & $7.37 \pm 1.12$ & $7.48 \pm 0.66$ & $7.00 \pm 1.80$ & $6.90 \pm 2.68$ & $7.28 \pm 2.03$ & $6.80 \pm 0.28$ & $7.45 \pm 1.63$ \\
\hline JB-middle ear [mm] & $2.33 \pm 0.28$ & $1.57 \pm 0.55$ & $2.01 \pm 0.50$ & $2.13 \pm 0.55$ & $2.10 \pm 0.14$ & $2.33 \pm 0.76$ & $2.10 \pm 0.14$ & $1.20 \pm 0.14$ \\
\hline JB-oval window [mm] & $7.33 \pm 1.52$ & $7.70 \pm 1.29$ & $6.40 \pm 0.40$ & $7.17 \pm 0.27$ & $6.76 \pm 0.70$ & $6.42 \pm 1.99$ & $7.05 \pm 1.06$ & $7.66 \pm 0.77$ \\
\hline
\end{tabular}

ME — middle ear; IAM — internal acoustic meatus; JB — jugular bulb; JB-middle ear — distance between the jugular bulb and middle ear; JB-oval window — distance between the jugular bulb and oval window; SD — standard deviation

right and left sides of bilateral tinnitus and control groups in both sexes ( $p s>0.05$, Table 4). Right ears of the cases with bilateral tinnitus were compared with right ears of the age and gender matched healthy control cases, and also separately left ears of the cases with bilateral tinnitus were compared with left ears of the age and gender matched healthy control cases. The mean CE for the stereological volume estimation of the cases with bilateral tinnitus was mean 0.041 for the right side, 0.044 for the left side and the control subject was mean 0.050 for the right side and 0.046 for the left side.

The JB levels on temporal bone were presented in Table 5. We did not encounter epitympanic JB level in cases with bilateral tinnitus. We revealed a significant difference between groups in respect to the distribution of JB levels $\left(\chi^{2}=10,705 ; p<0.05\right)$.
The JB was at the epitympanic level in 4 (16.7\%) controls of the control group compared to none $(0 \%)$ of the patients of the bilateral tinnitus group $\left(\chi^{2}=\right.$ $=4,029 ; p<0.05)$; and JB was at hypotympanic level in $13(36.1 \%)$ patients of the bilateral tinnitus group compared to $2(8.1 \%)$ controls of the control group $\left(\chi^{2}=4,537 ; p<0.05\right)$.

\section{DISCUSSION}

Tinnitus is complex complaint which is explained by multiple hypotheses. Results of this might be explained by the multi-etiological factors on tinnitus such as otologic, metabolic, systemic, iatrogenic or neurologic diseases [28, 31]. A good historical and physical examination, radiological investigation, and audiologic diagnose and examinations may of importance for finding out the causes [17]. Nonpulsatile tinnitus is 
Table 4. $P$ values for comparisons of ear groups in right and left sides.

\begin{tabular}{|c|c|c|c|c|}
\hline & \multicolumn{4}{|c|}{ Bilateral tinnitus - Control } \\
\hline & \multicolumn{2}{|c|}{ Females } & \multicolumn{2}{|c|}{ Males } \\
\hline & Right & Left & Right & Left \\
\hline Middle ear volume & 0.117 & 0.290 & 0.822 & 0.298 \\
\hline Internal acoustic meatus diameter & 0.899 & 0.658 & 0.548 & 0.242 \\
\hline Jugular bulb diameter & 0.924 & 0.767 & 0.700 & 0.333 \\
\hline JB-middle ear & 0.074 & 0.111 & 0.381 & 0.841 \\
\hline JB-oval window & 0.182 & 0.283 & 0.591 & 0.380 \\
\hline
\end{tabular}

JB-middle ear — distance between the jugular bulb and middle ear; JB-oval window — distance between the jugular bulb and oval window

Table 5. Level of the jugular bulb on temporal bone

\begin{tabular}{lcccc}
\hline Jugular bulb level & Bilateral tinnitus & Control & $\chi^{2}$ & $\mathbf{P}$ \\
\hline Epitympanic & & & $\mathbf{1 0 . 7 0}$ & $\mathbf{0 . 0 1 3}^{*}$ \\
Mesotympanic & $-(0 \%)$ & $4(16.7 \%)$ & 4.029 & $0.045^{* *}$ \\
Hypotympanic & $9(25 \%)$ & $7(29.2 \%)$ & 0.04 & $0.952^{* *}$ \\
Infratemporal & $13(36.1 \%)$ & $2(8.1 \%)$ & 4.537 & $0.033^{* *}$ \\
\hline
\end{tabular}

${ }^{*} \mathrm{P}$ value is given for $\chi^{2}$ crosstabulation test; ${ }^{* *} \mathrm{P}$ values are given forc 2 tests with Yates correction for continuity

more frequent type of tinnitus [17]. Personal factors are of importance for tinnitus. Personal perception and progress and response of patients with tinnitus may be variable. Some patients suffer from tinnitus much more than the others [12, 32]. It is challenging to find the underlying reasons of non-pulsatile type of tinnitus, because of its subjective nature. Acoustic neuroma or otologic disease such as Meniere's disease may be the reason of non-pulsatile subjective tinnitus. Furthermore, more common type is the subjective tinnitus with hearing loss but without any neurologic, otologic diseases or constitutional lesions [12, 24, 30]. In literature, genetic and physiological factors had been searched to solve these problems [12, 28, 31]. Middle ear aeration carries critical role for ossicular coupling and normal hearing [23]. After canal wall mastoidectomy, middle ear aeration become to affect hearing [12]. So, variances on middle ear volume may be the cause or aetiological factors of tinnitus.

Abnormalities on JB such as location anomalies, dehiscence, and diverticulitis may be the reason for pulsatile tinnitus [15]. Limited studies regarding the middle ear volume associated with tinnitus in literature. Osborn et al. [26] evaluated tympanic cavity volume in cases with aural atresia and searched for the role of the volume as a factor in determining surgical candidacy. They declared the mean age of cases at the time CT evaluation was 4.7 years. The mean tympanic cavity volume of the atretic ears was $0.34 \mathrm{cc}$ [26]. The mean tympanic cavity volume of the non-atretic ears was also 0.51 . In recent years, the tympanic cavity was evaluated on a project, and an abstract, and also a research on cases with tinnitus by Kurkcuoglu et al. [18-20]. Kurkcuoglu et al. [19] claimed that no statistically significant differences exist between gender in tympanic cavity volumes of the healthy subjects. Kahveci et al. [13] calculated middle ear volumes of the patients who suffered from unilateral tinnitus compared with healthy subjects, using stereological method. They found that mean left middle ear volume of the cases with unilateral tinnitus was $6.03 \mathrm{~cm}^{3}$ and the right one was $6.24 \mathrm{~cm}^{3}$. There was no significant difference between the cases with unilateral tinnitus and the control subjects. Contrary to the above studies, in the present study we assessed middle ear volumes of the cases with bilateral tinnitus according to gender and age compared with the healthy subjects. We found that mean right middle ear volume of the cases with bilateral tinnitus was $5.57 \mathrm{~cm}^{3}$ for males and $5.64 \mathrm{~cm}^{3}$ for females, and mean left middle ear volume of the cases with bilateral tinnitus 
was $5.87 \mathrm{~cm}^{3}$ for males and $5.65 \mathrm{~cm}^{3}$ for females. There were no significant differences between the cases with bilateral tinnitus and the control subjects according to the side of the body. Although volumetric results of both studies were similar except gender comparison of our study, Kahveci et al. [13] also measured the diameters of the internal acoustic meatus and the JB, which were larger in ears of the cases with unilateral tinnitus than in those of the healthy subjects. Kumral et al. [17] searched the anatomical reasons in the aetiology of the tinnitus in the normal-hearing ears. Patients in their study had bilateral tinnitus and most of the patients could not define the location, the time, the duration, and the severity of the tinnitus. The females were more than the males in the tinnitus group, consistently with the literature. The results of the study also showed that there were no significant differences in the measurements of internal acoustic canal between the control and tinnitus groups. The comparison of the measurements within the tinnitus groups did not show significant difference in the right and left internal acoustic canals. The authors claimed that in tinnitus cases with normal hearing temporal bone tomography does not carry important information and is not cost effective [17].

We did not detect any statistical differences between the cases with bilateral tinnitus and control subjects in terms of diameters of the internal acoustic meatus and the JB according to the side of the body. Contrary to the above studies, we also firstly evaluated JB levels as epitympanic, mesotympanic, hypotympanic and infratemporal. None of the patients with bilateral tinnitus had epitympanic JB level, while controls had epitympanic JB. In addition, the hypotympanic JB level was more prevalent. This difference should be investigated with repeated studies containing higher number of cases.

The distance between JB and anatomical some landmarks like middle ear and oval window. In addition, inherent methodical limitations of the different methods would be mentioned. The reasons might be related to small sample sizes of most studies, choosing of the control groups (e.g. whether hearing loss or depressive symptoms are controlled for) and to the heterogeneity of tinnitus [27].

\section{CONCLUSIONS}

We used the stereological method, because the method is simple, safe, unbiased, and cheap. The point counting approach is also rapid. The obtained CE level of our study was quite low. This low level may be obtained by CT slices in frequent and consequent intervals and decreasing the distance between two points of the grid for counting a large amount of points per area. With regard to the aging process, further investigations are required with a larger sample size in order to support this data.

\section{Acknowledgements}

The authors would like to thank Mustafa Deniz Yilmaz, Ayse Canan Yazici and Deniz Sidi for their kindly support and help.

\section{REFERENCES}

1. Acer N, Sahin B, Usanmaz M, et al. Comparison of point counting and planimetry methods for the assessment of cerebellar volume in human using magnetic resonance imaging: a stereological study. Surg Radiol Anat. 2008; 30(4): 335-339, doi: 10.1007/s00276-008-0330-9, indexed in Pubmed: 18292960.

2. Adjamian P, Sereda M, Hall DA. The mechanisms of tinnitus: perspectives from human functional neuroimaging. Hear Res. 2009; 253(1-2): 15-31, doi: 10.1016/j. heares.2009.04.001, indexed in Pubmed: 19364527.

3. Axelsson A, Ringdahl A. Tinnitus - a study of its prevalence and characteristics. Br J Audiol. 1989; 23(1): 53-62, doi: 10.3109/03005368909077819, indexed in Pubmed: 2784987.

4. Barwood CHS, Wilson WJ, Malicka AN, et al. The effect of rTMS on auditory processing in adults with chronic, bilateral tinnitus: a placebo-controlled pilot study. Brain Stimul. 2013; 6(5): 752-759, doi: 10.1016/j.brs.2013.01.015, indexed in Pubmed: 23453932.

5. Bauer CA. Mechanisms of tinnitus generation. Curr Opin Otolaryngol Head Neck Surg. 2004; 12(5): 413-417, indexed in Pubmed: 15377954.

6. Cherian $\mathrm{K}$, Cherian N, Cook C, et al. Improving tinnitus with mechanical treatment of the cervical spine and jaw. J Am Acad Audiol. 2013; 24(7): 544-555, doi: 10.3766/ jaaa.24.7.3, indexed in Pubmed: 24047942.

7. De Ridder D, Vanneste S, Kovacs S, et al. Transcranial magnetic stimulation and extradural electrodes implanted on secondary auditory cortex for tinnitus suppression. J Neurosurg. 2011; 114(4): 903-911, doi: 10.3171/2010.11. JNS10197, indexed in Pubmed: 21235318.

8. Deniz M, Bayazit YA, Celenk F, et al. Significance of serotonin transporter gene polymorphism in tinnitus. Otol Neurotol. 2010; 31(1): 19-24, doi: 10.1097/ MAO.0b013e3181c2dcbc, indexed in Pubmed: 19924014.

9. Ekinci N, Acer N, Akkaya A, et al. Volumetric evaluation of the relations among the cerebrum, cerebellum and brain stem in young subjects: a combination of stereology and magnetic resonance imaging. Surg Radiol Anat. 2008; 30(6): 489-494, doi: 10.1007/s00276-008-0356-z, indexed in Pubmed: 18478176. 
10. Fortune DS, Haynes DS, Hall JW. Tinnitus. Current evaluation and management. Med Clin North Am. 1999; 83(1): 153-62, x, indexed in Pubmed: 9927967.

11. Gocmen-Mas N, Kahveci O, Karabekir S, et al. Stereological volumetric evaluation of the cerebellum in benign paroxysmal positional vertigo. Neurosciences (Riyadh). 2011; 16(4): 358-362, indexed in Pubmed: 21983380.

12. Haginomori SI, Takamaki A, Nonaka R, et al. Postoperative aeration in the middle ear and hearing outcome after canal wall down tympanoplasty with soft-wall reconstruction for cholesteatoma. Otol Neurotol. 2009; 30(4): 478-483, doi: 10.1097/MAO.0b013e31819e634a, indexed in Pubmed: 19373119.

13. Kahveci OK, Gocmen-Mas N, Okur N, et al. Investigation of temporal bone asymmetry in cases with unilateral tinnitus: morphometric and multicentric clinical study. Folia Morphol. 2013; 72(1): 22-28, indexed in Pubmed: 23749707.

14. Kalkan E, Cander B, Gul M, et al. Prediction of prognosis in patients with epidural hematoma by a new stereological method. Tohoku J Exp Med. 2007; 211(3): 235-242, indexed in Pubmed: 17347548.

15. Khedr EM, Abo-Elfetoh N, Rothwell JC, et al. Contralateral versus ipsilateral rTMS of temporoparietal cortex for the treatment of chronic unilateral tinnitus: comparative study. Eur J Neurol. 2010; 17(7): 976-983, doi: 10.1111/j.14681331.2010.02965.x, indexed in Pubmed: 20236173.

16. Krishnan A, Mattox DE, Fountain AJ, et al. CT arteriography and venography in pulsatile tinnitus: preliminary results. AJNR Am J Neuroradiol. 2006; 27(8): 1635-1638, indexed in Pubmed: 16971601.

17. Kumral TL, Yıldırım G, Yılmaz HB, et al. Is it necessary to do temporal bone computed tomography of the internal auditory canal in tinnitus with normal hearing? ScientificWorldJournal. 2013; 2013: 689087, doi: 10.1155/2013/689087, indexed in Pubmed: 24379749.

18. Kurkcuoglu A, Kurkcuoglu S, Pelin C, et al. Volumetric evaluation of Tympanic cavity in the patients with Tinnitus: a stereological study. Surg Radiol Anat. 2011; 29: 511-526.

19. Kürkçüoğlu A, Kürkçüoğlu SS, Inançli HM, et al. Measurement of tympanic cavity volume by the Cavalieri principle in Turkish population. Kulak Burun Bogaz Ihtis Derg. 2010; 20(3): 137-141, indexed in Pubmed: 20465539.

20. Kurkcuoglu A, Pelin C, Zagyapan R, et al. Volumetric evaluation of Tympanic cavity in the patients with Tinnitus. Baskent Univeristy Scientific Research Project KA 07/60, Ankara. 2007.

21. Lanting $C P$, de Kleine $E$, van Dijk P. Neural activity underlying tinnitus generation: results from PET and fMRI. Hear Res.
2009; 255(1-2): 1-13, doi: 10.1016/j.heares.2009.06.009, indexed in Pubmed: 19545617.

22. Mehall $\mathrm{CJ}$, Wilner HI, LaRouere MJ. Pulsatile tinnitus associated with a laterally placed sigmoid sinus. AJNR Am J Neuroradiol. 1995; 16(4 Suppl): 905-907, indexed in Pubmed: 7611070.

23. Merchant SN, Ravicz ME, Voss SE, et al. Analysis of middle ear mechanics and application to diseased and reconstructed ears. Am J Otol. 1997; 18(2): 139-154, indexed in Pubmed: 9093668.

24. Møller AR. Tinnitus: presence and future. Prog Brain Res. 2007; 166: 3-16, doi: 10.1016/50079-6123(07)66001-4, indexed in Pubmed: 17956767.

25. Nyengaard JR, Marcussen N. The number of glomerular capillaries estimated by an unbiased and efficient stereological method. J Microsc. 1993; 171 (Pt 1): 27-37, indexed in Pubmed: 8366524.

26. Osborn AJ, Oghalai JS, Vrabec JT. Middle ear volume as an adjunct measure in congenital aural atresia. Int J Pediatr Otorhinolaryngol. 2011; 75(7): 910-914, doi: 10.1016/j. ijporl.2011.04.004, indexed in Pubmed: 21570132.

27. Schecklmann M, Lehner A, Poeppl TB, et al. Auditory cortex is implicated in tinnitus distress: a voxel-based morphometry study. Brain Struct Funct. 2013; 218(4): 1061-1070, doi: 10.1007/s00429-013-0520-z, indexed in Pubmed: 23435735.

28. Seidman MD, Standring RT, Dornhoffer JL. Tinnitus: current understanding and contemporary management. Curr Opin Otolaryngol Head Neck Surg. 2010; 18(5): 363-368, doi: 10.1097/MOO.0b013e32833c718d, indexed in Pubmed: 20625292.

29. Shargorodsky J, Curhan GC, Farwell WR. Prevalence and characteristics of tinnitus among US adults. Am J Med. 2010; 123(8): 711-718, doi: 10.1016/j.amjmed.2010.02.015, indexed in Pubmed: 20670725.

30. Shiley SG, Folmer RL, McMenomey SO. Tinnitus and hyperacusis; in: Cummings CW, Flint PW, Haughey BH, Robbins KT, Thomas JR, Harker LA (eds): Otolaryngology-head and neck surgery. Mosby Year Book, St. Louis 2005: 2832-2847.

31. Sismanis A. Pulsatile tinnitus: contemporary assessment and management. Curr Opin Otolaryngol Head Neck Surg. 2011; 19(5): 348-357, doi: 10.1097/ MOO.0b013e3283493fd8, indexed in Pubmed: 22552697.

32. Welch D, Dawes PJD. Personality and perception of tinnitus. Ear Hear. 2008; 29(5): 684-692, doi: 10.1097/ AUD.0b013e318177d9ac, indexed in Pubmed: 18596645. 